\title{
A simple and effective strategy for improving junior doctors' knowledge of intravenous fluid therapy
}

This article was published in the following Dove Press journal:

Clinical Audit

18 February 2014

Number of times this article has been viewed

\author{
Anand Prakash \\ Swayamprakasam' \\ Pooja Bijoor ${ }^{2}$ \\ Usman Khalid ${ }^{3}$ \\ Muhammad Sagheer Rana ${ }^{4}$ \\ Richard Boulton ${ }^{5}$ \\ Amanda Taylor 6 \\ 'Department of Trauma and \\ Orthopaedics, Royal Oldham \\ Hospital, Rochdale Road, Oldham, \\ UK; ${ }^{2}$ Department of Otolaryngology, \\ Manchester Royal Infirmary, Oxford \\ Road, Manchester, UK; ${ }^{3}$ Department \\ of Transplant Surgery, University \\ Hospital of Wales, Cardiff, UK; ${ }^{4}$ GP \\ Specialty Training Programme, East \\ Midlands, Rutland House, Meridian \\ Business Park, Leicester, UK; \\ ${ }^{5}$ Department of General Surgery, \\ Basildon Hospital, Essex, UK; \\ ${ }^{6}$ Department of General Surgery, \\ Milton Keynes Hospital NHS \\ Foundation Trust, Milton Keynes, UK
}

Correspondence: Anand Prakash Swayamprakasam

Department of Trauma and Orthopaedics, Royal Oldham Hospital, Rochdale Road, Oldham, OLI 2JH, UK Tel +44016 I6440420 Email aps49@doctors.org.uk
Background: The purpose of this study was to assess the effectiveness of a single focused teaching session in improving junior doctors' knowledge of intravenous fluid therapy.

Methods: A questionnaire was developed from the current national guidelines on perioperative intravenous fluid therapy, ie, the 2008 British Consensus Guidelines on Intravenous Fluid Therapy for Adult Surgical Patients. The questionnaire was administered to foundation year 1 doctors at baseline. Subsequently a teaching session on intravenous fluid therapy was organized. The participants completed the questionnaire immediately after and again 2-5 weeks after the teaching session. The main outcome measure was the change in mean score after the intervention.

Results: The mean pre-education score was 4.3 (36\%). The mean post-education scores immediately and an average of 22 days after the teaching session were $10.3(85 \%)$ and $9.5(79 \%)$, respectively.

Conclusion: A single focused teaching session is a simple and effective way of improving junior doctors' knowledge of intravenous fluid therapy. We recommend that a teaching session on intravenous fluids be integrated into the teaching program for all junior doctors.

Keywords: intravenous fluids, British Consensus Guidelines on Intravenous Fluid Therapy for Adult Surgical Patients, doctors' knowledge, education

\section{Introduction}

Erroneous intravenous fluid therapy is a source of perioperative morbidity and mortality. The 1999 National Confidential Enquiry into Perioperative Deaths discovered that in $20 \%$ of perioperative deaths there was either unrecognized/untreated fluid imbalance or poor documentation of fluid balance. ${ }^{1}$ Recent studies have shown that in most surgical units, preregistration house officers (equivalent to foundation year 1 [FY1] doctors) are given the major responsibility for prescribing intravenous fluids, even though their knowledge base may be inadequate. ${ }^{2-4}$ Training FY1 doctors in intravenous fluid therapy is required to improve their knowledge and reduce the morbidity and mortality associated with erroneous intravenous fluid therapy. In a 2002 survey of consultant surgeons, the most favored training method for improving perioperative fluid therapy was focused practical training in the form of problem-based ward rounds. ${ }^{3}$ Since then, the landscape of medical training has been altered by the European Working Time Directive. The reduction in clinical hours following implementation of this directive limits the opportunities for practical training on the job. ${ }^{5}$ Hence, alternative strategies are required. This audit evaluated whether a single focused teaching session, based on the current national guidelines for perioperative fluid therapy, could improve the knowledge of FY1 doctors. 


\section{Materials and methods}

\section{Participants}

All FY1 doctors at a district general hospital in south central England were requested to take part in this study. Doctors' participation was voluntary, and no ethical approval was required.

\section{Intervention}

A single focused teaching session on perioperative fluid therapy was organized with the approval of the hospital's foundation program director. The teaching session was designed by a team made up of a surgical trainee, an anesthetics and intensive care trainee, and a consultant surgeon. The teaching session was designed taking into consideration the GIFTASUP (Guidelines on Intravenous Fluid Therapy for Adult Surgical Patients) and pertinent education principles. The duration of the teaching session was one hour. This time was divided equally in two parts. In the first part, learners were taught about the theoretical aspects of perioperative intravenous fluid therapy. In the second part of session, clinical vignettes were used and learners were encouraged to work through these examples. The facilitator of the teaching session was the anesthetics and intensive care specialist trainee.

The major educational principles that were made use of are discussed below. A major challenge for any teaching session is motivating the learners. If learners are not adequately motivated by the teaching session, they fail to learn, because they do not undertake cognitive processing. This phenomenon is termed generative underutilization. To ensure that the junior doctors were motivated by the teaching session, it was designed to be relevant and of value to them. Hence, the teaching session was focused on intravenous fluid prescription issues that junior doctor encounter in their day-to-day work. The level of cognitive processing is important, with higher levels leading to better learning and long-term retention. To promote a higher level of processing by the learners, they were encouraged to work through a number of different clinical vignettes. Managing cognitive load is essential, otherwise learners are overwhelmed by the information. Hence, the teaching session was segmented into two parts. Segmentation is an educational process in which a teaching session is broken into smaller parts. It is postulated that segmentation avoids cognitive overload by allowing time for information processing between the segments.

\section{Evaluation of the intervention}

The outcome data comprised the doctors' answers to confidential, self-completed questionnaires at baseline, immediately after, and again 2-5 weeks following the teaching session. Participants were unaware that the questionnaire would be repeated immediately after and again a few weeks following the teaching session. The questionnaire was developed from the current national GIFTASUP. The final questionnaire contained 12 best-of-five, multiple-choice questions. The topics covered in the questionnaire were: daily fluid and electrolyte requirements, common surgical conditions, assessment of volume status, and specific preoperative and postoperative considerations. Each questionnaire was allocated a mark out of 12 (minimum score 0 , maximum score 12). The main outcome measure was the change in mean score after the intervention.

\section{Results}

All 26 FY1 doctors in the hospital completed the pre-education questionnaire. Twenty attended the teaching session and completed the questionnaire immediately after and on average 22 (range 14-31) days after the teaching session. The mean pre-education score was 4.3 (36\%). The mean score immediately after the teaching session was $10.3(85 \%)$. The mean score at an average of 22 days after the teaching session was $9.5(79 \%)$. Figure 1 gives a breakdown of the scores in terms of the four topics covered in the questionnaire.

\section{Discussion}

This audit shows that: FY1 doctors' baseline knowledge of intravenous fluid therapy was inadequate (36\%); there was a significant improvement (85\%) following a single focused teaching session; and this knowledge was retained (79\%). Inadequate teaching on intravenous fluids is believed to be responsible for the poor baseline knowledge. This view is supported by the fact that a single teaching session on intravenous fluids resulted in a marked improvement in FY1 doctors' understanding, ie, an increase from $36 \%$ to $85 \%$. The focused teaching session taught participants the theoretical aspects of intravenous fluid therapy and its implications for clinical practice in a clear and concise manner. All of these factors are believed to be responsible for the improved understanding created by the teaching session. Subsequent clinical exposure and continued practice in fluid management are believed to be responsible for the knowledge being retained.

Our audit benefits from being the first to examine the efficacy of a single focused teaching session in improving FY1 doctors' knowledge of intravenous fluid therapy. As such, it determines the efficacy of a training method that can be delivered within the time constraints of European Working Time Directive. Further, the efficacy of a single 


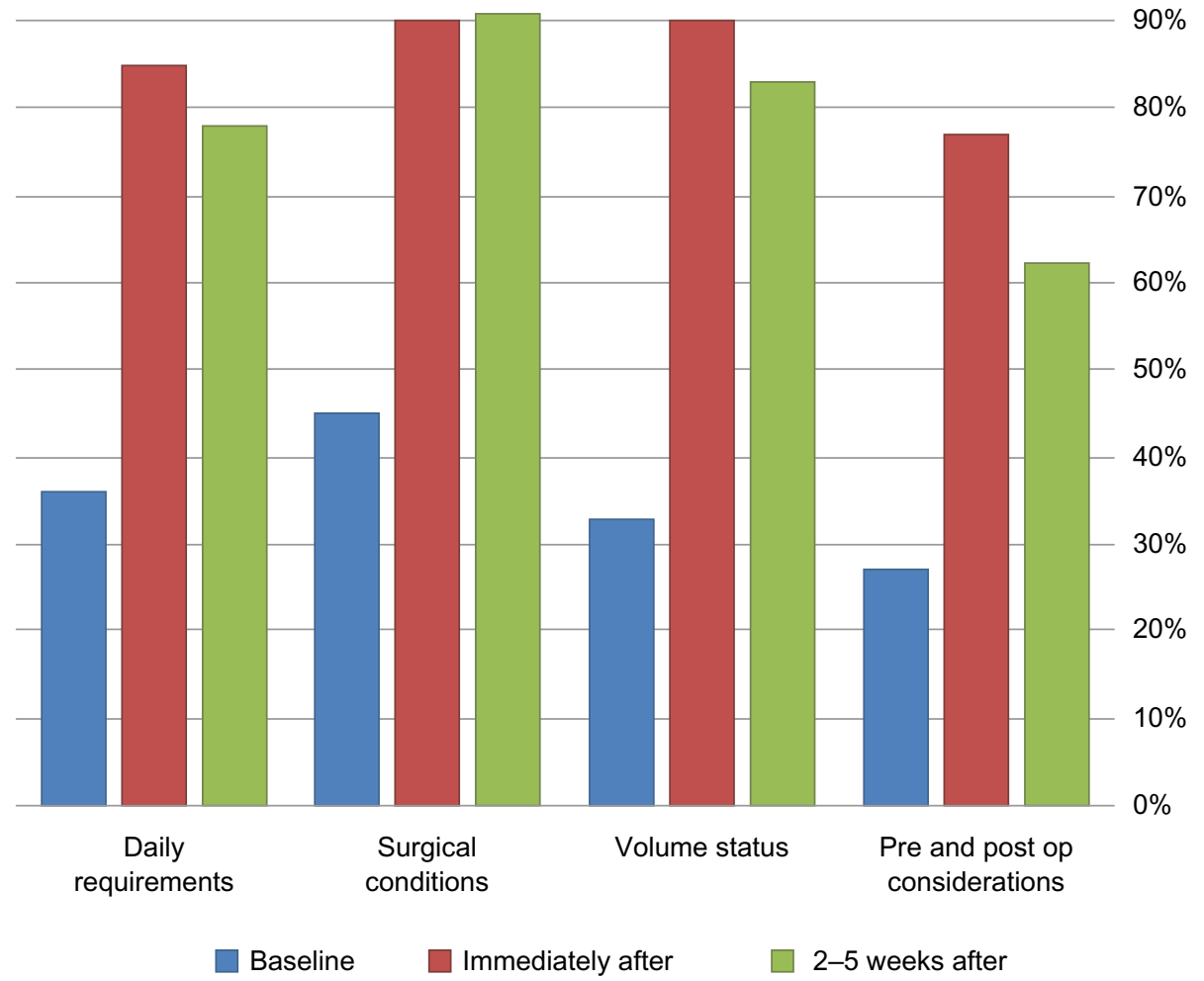

Figure I Comparison of participants' scores at baseline, immediately after, and 2-5 weeks after the teaching session.

focused teaching was assessed by whether the knowledge was retained as opposed to just testing immediate recall.

The limitations of the audit include its small sample size, the lack of validated questionnaire(s) to assess knowledge of intravenous fluid therapy, the short duration at which retention of knowledge was tested, and the lack of assessment of the impact on clinical practice. Hence, future work should examine participants' knowledge at intervals of 3, 6, and 12 months to determine the need for continued and repeated training in this important subject. Future research is also

Table I Take home message: what fluid should be used and when

\begin{tabular}{ll}
\hline Fluid & Uses \\
\hline $\begin{array}{l}\text { A balanced crystalloid: } \\
\text { Hartmann's or Ringer's }\end{array}$ & $\begin{array}{l}\text { First-line for surgical patients needing } \\
\text { maintenance fluids } \\
\text { lactate }\end{array}$ \\
$\begin{array}{l}\text { To replace abnormal losses from diarrhea, } \\
\text { ileostomy, small and large bowel obstruction, } \\
\text { peritonitis, and acute pancreatitis } \\
\text { An unbalanced } \\
\text { crystalloid: }\end{array}$ & $\begin{array}{l}\text { Limited to patients needing maintenance } \\
\text { or replacement fluids who are also } \\
\text { hypochloremia, eg, gastric outflow obstruction } \\
\text { Colloid }\end{array}$ \\
hlood & $\begin{array}{l}\text { Limited to patients needing resuscitative } \\
\text { fluid therapy } \\
\text { For resuscitation cases, where there has } \\
\text { been blood loss }\end{array}$ \\
\hline
\end{tabular}

required to determine if the knowledge gained as result of the teaching session alters fluid prescribing habits and whether this translates into better patient outcomes.

Awad et al demonstrated that a structured workshop on fluid and electrolyte balance was effective in improving participants' knowledge. ${ }^{6}$ However, the magnitude of the observed effect (from a pre-education score of 19.7/30 to a post-education score of 24.6/30) was less than in our audit (from a pre-education score of $4.3 / 12$ to a post-education score of 10.3/12). This may be due to a higher pre-education score in the study by Awad et al. In their study, participants were specialty year 1 and 2 trainees, ${ }^{6}$ who have $2-3$ years more experience than that FY1 trainees who took part in our audit. In addition, participants in the study by Awad et al were given online access to the teaching material prior to administration of the pre-education multiple-choice questions and all questions were based on the content of the teaching material. ${ }^{6}$ Both of these factors are likely to responsible for the higher pre-education score observed in the study by Awad et al.

In conclusion, a single focused teaching session appears to be a simple and effective way of improving foundation doctors' knowledge of intravenous fluid therapy. Safe 
prescription of intravenous fluids is an important competency requirement for foundation doctors. ${ }^{7}$ The safe prescription of different intravenous fluids is highlighted in Table 1. We recommend that a focused teaching session on intravenous fluid therapy is integrated into the teaching program for all foundation doctors. This is likely to receive support from these doctors, because our experience was that the teaching session was well attended.

\section{Author contributions}

APS, UK, and AT conceived and designed the study; APS and $\mathrm{PB}$ recruited participants and wrote the manuscript; UK, MSR, and RB designed the teaching session; MSR delivered the teaching; APS, UK, RB, and AT analyzed the data; and UK, MSR, RB, and AT commented on drafts and revised the manuscript. All authors read and approved the final paper. APS is the study guarantor.

\section{Disclosure}

All authors declare that they received no support from any organization for the submitted work; have had no financial relationships with any organizations that might have an interest in the submitted work in the previous 3 years; and have no other relationships or activities that could appear to have influenced the submitted work. This work received no specific funding from any funding agency in the public, commercial, or non-profit sectors.

\section{References}

1. Callum KG, Gray AJG, Hoile RW, et al. Extremes of Age: The 1999 Report of the National Confidential Enquiry into Perioperative Deaths. National Confidential Enquiry into Perioperative Deaths; 1999. Available from: http://www.ncepod.org.uk/pdf/1999/99full.pdf. Accessed October 27, 2013.

2. Lobo DN, Dube MG, Neal KR, Simpson J, Rowlands BJ, Allison SP. Problems with solutions: drowning in the brine of an inadequate knowledge base. Clin Nutr. 2001;20(2):125-130.

3. Lobo DN, Dube MG, Neal KR, Allison SP, Rowlands BJ. Peri-operative fluid and electrolyte management: a survey of consultant surgeons in the UK. Ann R Coll Surg Engl. 2002;84(3):156-160.

4. Walsh SR, Walsh CJ. Intravenous fluid-associated morbidity in postoperative patients. Ann R Coll Surg Engl. 2005;87(2):126-130.

5. Benes V. The European Working Time Directive and the effects on training of surgical specialists (doctors in training): a position paper of the surgical disciplines of the countries of the EU. Acta Neurochir (Wien). 2006;148(11):1227-1233.

6. Awad S, Allison SP, Lobo DN. Fluid and electrolyte balance: the impact of goal directed teaching. Clin Nutr. 2008;27(3):473-478.

7. The Foundation Programme. The UK Foundation Programme Curriculum. Available from: http://www.foundationprogramme.nhs.uk/ download.asp?file=FP_Curriculum_2012_WEB_FINAL.PDF. Accessed December 9, 2012
Clinical Audit

\section{Publish your work in this journal}

Clinical Audit is an international, peer-reviewed, open access journal focusing on the processes and outcomes of clinical audit in any area of healthcare. All aspects of patient care are addressed within the journal and practitioners from all disciplines are invited to submit their work. Areas covered include: Publication of audits; How an audit has changed practice;

\section{Dovepress}

Practical tips on how to do audits and to avoid pitfalls; How audits have changed patient care; Calls and justifications for new audits. The manuscript management system is completely online and includes a very quick and fair peer-review system, which is all easy to use. Visit http://www.dovepress. com/testimonials.php to read real quotes from published authors. 